\title{
Research and Construction of Supply Chain Information Quality Index System based on PSP/IQ Model
}

\author{
Fan Shuhai \\ Nanjing Tech University \\ NJ 210009, China \\ MIT Quality Information Program “Data Quality \& Info \\ Security” Lab, Cambridge, MA, USA
}

\author{
Lv Qingwen \\ Nanjing Tech University \\ NJ 210009, China \\ 347910071@qq.com
}

\author{
Wei Xia* \\ Nanjing Tech University \\ NJ 210009, China
}

\author{
Zhao Lingling \\ Nanjing Tech University \\ NJ 210009, China
}

\author{
$\mathrm{Xu}$ Wenhao \\ Nanjing Tech University \\ NJ 210009, China
}

\begin{abstract}
Based on the correlation theory of information quality, the standard construction method of information quality measurement and evaluation in the supply chain of equilibrium quantity is established by using PS P/I Q model. Firstly, through the analysis of PS P/I Q model index, it classifies them into the four first-level index, and builds the evaluation index frame. Then, the network layer sub-analysis method, through the volume survey, expert grading method, and so on, from the qualitative and quantitative aspects of the information quality index weight re-calculation. At last, a more complete standard for evaluating the information quality of the supply chain is established.
\end{abstract}

Keywords-Information quality, Supply chain management, ANP, The quality assessment

\section{INTRODUCTION}

In the context of the Internet and big data era, organizations are faced with a growing amount of information, but the quality of such information cannot meet the needs of users. Poor information brings invisible losses to enterprises that are difficult to measure. For companies, the motivation to understand and improve the quality of information is more urgent than ever before.

In the supply chain, information exchange between enterprises is extremely close, and more and more nodal enterprises are no longer in direct contact with upstream and downstream enterprises (such as customers and suppliers), but cooperate and contact with information as the main body of exchange, just like exchanging goods and services. In this mode, there are many problems in the management of information quality: enterprises obtain information from many sources, the quality of information management level of each enterprise is uneven, the processing and integration of information is cumbersome and difficult; The up-down transmission of information requires high efficiency, accuracy and other requirements, and it is difficult to quantify the losses caused by poor information quality: the acquisition, processing, storage, transmission and other aspects of each link require enterprises to invest a lot of costs: there is no unified and perfect enterprise information quality measurement standards.
Based on the above, PSP/IQ model is adopted in this paper to establish an indicator framework to measure the quality of information in the supply chain. In consideration of the mutual influence between the indicators, ANP (network analytic hierarchy process) was introduced to give weight to the information quality indicators, and a relatively complete evaluation standard for measuring the supply chain information quality was established.

\section{OVERVIEW OF INFORMATION QUALITY MANAGEMENT}

When early scholars studied the definition of information quality, they cited Juran's definition of quality -- "fitness for use" or "degree of satisfaction to users "[1]. In terms of information quality management research, Richard Y Wang ${ }^{[2]}$ proposed total data quality management (TDQM) method. Firstly, he proposed to regard information as a product and study it from the perspective of quality management. $\mathrm{Krol}^{[3]}$, et al. established an information quality management framework for data map production.

As the theoretical research on information quality becomes more and more mature, experts and scholars in various fields begin to study the relevant problems and solutions of data in their cities.

In the past research, the research on supply chain information quality is very limited. Mouzhi $\mathrm{Ge}^{[4]}$, et al. studied the influence of information quality on supply chain decision making. Through the bullwhip effect experiment to control the quality of each index of information transmission up and down, the overall benefit of the final supply chain is compared, and the influence of the quality difference of different indicators on the final decision is analyzed. It is verified that the accuracy and completeness of information have a significant impact on the quality of decision-making. Although the consistency of information has little impact on the quality of decision-making, the consistency of information will enhance its accuracy, which is reflected in the fact that the consistency and accuracy of information jointly affect the quality of decision-making. In addition, Li Chao ${ }^{[5]}$, et al. studied the measurement dimension and evaluation method of information quality in hydrological 
information system, added the influence of timeliness, and established an information quality evaluation model with the quality and timeliness of information as the main influencing factors.

\section{SUPPLY CHAIN INFORMATION QUALITY P SP/I Q MODEL CONSTRUCTION}

This paper adopts the PSP/IQ model established by Beverly and Diane ${ }^{[6]}$ for research. PSP/IQ mode (product and service performance model for information quality), It is to point to the management of information quality gives consideration to both information product and information service. The service function of information is often neglected in previous studies, but it is undeniable that products and services are two important aspects of information quality. From the perspective of engineering, the productiveness of information is reflected in the fact that information can be produced, stored, sold, used and reused. Information also has an invisible service. Product quality of information refers to the specification standard that certain characteristics of information set up by product manufacturer or manager need to be met. These features can often be measured. Service quality generally describes that there is no standard or objective measurement of information product characteristics. This kind of information quality evaluation index usually requires that information can bring higher practicability and added value for users. Sixteen representative information quality measurement indexes were selected by analyzing the previous studies of scholars. All the indicators are classified as health information, useful information, reliable information and availability information under the four first-level indicators of compliance with specifications and meeting or exceeding user expectations.

In this study, 20 graduate students and teachers majoring in supply chain and logistics management and 4 employees engaged in the implementation of supply chain information system were interviewed. The final classification results of measurement indicators are shown in Table I.

TABLE I. SUPPLY CHAIN INFORMATION QUALITY INDEX SySTEM

\begin{tabular}{|c|c|c|}
\hline Target & First level index & Two level index \\
\hline \multirow{16}{*}{$\begin{array}{l}\text { A supply chain } \\
\text { information } \\
\text { quality evaluation } \\
\text { index system }\end{array}$} & \multirow{4}{*}{$\begin{array}{l}\text { B1 sound } \\
\text { information }\end{array}$} & C11 consistency \\
\hline & & C12 accuracy \\
\hline & & C13 redundancy \\
\hline & & C14 integrated \\
\hline & \multirow{3}{*}{$\begin{array}{l}\text { B2 useful } \\
\text { information }\end{array}$} & C21 adequacy \\
\hline & & C22 completeness \\
\hline & & C23 simplicity \\
\hline & \multirow{5}{*}{$\begin{array}{l}\text { B3 reliable } \\
\text { information }\end{array}$} & C31 accessibility \\
\hline & & $\begin{array}{c}\mathrm{C} 32 \\
\text { maintainability } \\
\end{array}$ \\
\hline & & C33 reusability \\
\hline & & C34 security \\
\hline & & C35 timeliness \\
\hline & \multirow{4}{*}{$\begin{array}{l}\text { B4 available } \\
\text { information }\end{array}$} & $\begin{array}{c}\text { C41 } \\
\text { interpretability }\end{array}$ \\
\hline & & $\begin{array}{c}\text { C42 } \\
\text { comprehensibility }\end{array}$ \\
\hline & & C43 profitability \\
\hline & & C44 reliability \\
\hline
\end{tabular}

\section{INFORMATION QUALITY INDEX WEIGHT MEASUREMENT}

\section{A. Network analytic hierarchy process}

The measurement dimension of information quality is often not completely independent of each other, and there is an interaction between different information dimensions, for example, the consistency of information will strengthen its accuracy, which is reflected in the fact that the consistency and accuracy of information jointly affect the quality of decision-making ${ }^{[5]}$; There is an inverse correlation between the accuracy and timeliness of information. Therefore, in the evaluation of information quality, the mutual influence relations among various indicators should be taken into account comprehensively, especially under different categories of indicators. Therefore, this paper employs the Analytic Network Process (ANP) to analyze the weight. ANP is an Analytic Hierarchy Process based on Analytic Hierarchy Process (AHP). AHP only considers the influence of the upper layer on the next layer, and develops to consider not only the influence of the upper layer on the next layer, but also the feedback effect of the next layer on the upper layer, as well as the dependency and influence relationship within and between element sets ${ }^{[7]}$. ANP is a decisionmaking method adapted to non-independent hierarchical structure, which is divided into control layer and network layer: control layer and network layer. The control layer consists of target and criterion layers. The criterion layer is independent of each other and its weight can be calculated by traditional AHP method. The network layer presents the network structure in which various factors influence each other. As this part requires the use of super matrix, weighted super matrix and other complex computing processes, super decisions (SD) software is used to assist calculation.

\section{B. ANP algorithm calculation steps}

\section{1) Construct pairwise comparison judgment matrix}

When ANP is used for decision analysis, decision makers need to compare the importance degree of all indicators with their advantages. Before that, the influence relationship between all indicators was studied through expert interviews, as shown in Table II.

TABLE II. SUPPLY CHAIN INFORMATION QUALITY INDEX CORRELATION QUESTIONNAIRE

\begin{tabular}{|c|c|c|c|c|c|c|c|c|c|c|c|c|c|c|c|c|c|}
\hline & \multicolumn{4}{|c|}{ B1 } & \multicolumn{3}{|c|}{ B2 } & \multicolumn{5}{|c|}{ B3 } & \multicolumn{4}{|c|}{ B4 } \\
\hline & & C11 & $\mathrm{C} 12$ & C13 & C14 & C21 & C22 & C23 & C31 & C32 & C33 & C34 & C35 & C41 & C42 & C43 & C44 \\
\hline \multirow{4}{*}{ B1 } & C11 & & & & $v$ & & v & & & & & & & & & & $\checkmark$ \\
\hline & C12 & $\sqrt{ }$ & & & & & & $\sqrt{ }$ & & & $\checkmark$ & & & V & V & $\sqrt{ }$ & V \\
\hline & $\mathrm{C} 13$ & & $\sqrt{ }$ & & & V & $\sqrt{ }$ & $\sqrt{ }$ & & & & & & & & & 1 \\
\hline & C14 & & & & & $\sqrt{ }$ & & & 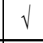 & V & & $\sqrt{ }$ & & & & $\sqrt{ }$ & \\
\hline \multirow{3}{*}{$B 2$} & C21 & & $\sqrt{ }$ & V & & & $\sqrt{ }$ & & & & & & & & & & \\
\hline & C22 & & & $\sqrt{ }$ & & $\sqrt{ }$ & & $\sqrt{ }$ & & & & & & V & & $\sqrt{ }$ & V \\
\hline & C23 & & $\checkmark$ & & & & & & & & & & & & $\checkmark$ & & \\
\hline \multirow{5}{*}{ B3 } & C31 & & & & & & & & & & & $\sqrt{ }$ & & & & & $V$ \\
\hline & C32 & & & & $\sqrt{ }$ & & & & & & & $\sqrt{ }$ & & & & & 1 \\
\hline & C33 & & & & & & & & & & & & $\sqrt{ }$ & & & $\checkmark$ & \\
\hline & C34 & & & & & & & & $\checkmark$ & & & & & & & & $\checkmark$ \\
\hline & C35 & & & & & & & & & & $\checkmark$ & & & & & $\checkmark$ & \\
\hline \multirow{4}{*}{ B4 } & C41 & & & & & & & & & & & & & & & & $\checkmark$ \\
\hline & C42 & & & & & & & & & & & & & $\checkmark$ & & & \\
\hline & C43 & & & & & & & & & & & & & & & & \\
\hline & C44 & & $\sqrt{ }$ & & & & $\checkmark$ & & & & & & V & $\checkmark$ & $\checkmark$ & $\checkmark$ & \\
\hline
\end{tabular}


The correlation degree of first-level indicators (criterion level indicators) was statistically analyzed (the number of check marks was statistically analyzed), and pair-wise judgment matrix comparison was conducted if the number was greater than 0 . The correlation degree of the secondary index (criterion level index) was statistically analyzed, and pair-wise judgment matrix comparison was conducted if the value was greater than 1 (in Table II, the part marked by gray shadow was the secondary index that should be pair-wise comparison of the matrix to meet the requirements).

Instructions: If the left index has an effect on the top index, then check the corresponding box.

This paper adopts the conference discussion method to judge the critical process according to the scale from 1 to 9 (when the consistency test CR is less than or equal to 0.1 , it is valid weight, otherwise, it is invalid), as shown in Table III.

TABLE III. EXAMPLES OF RATING SCALE METHODS FROM 1 TO 9

\begin{tabular}{|l|c|c|c|c|}
\hline & C41 interpretability & C42 comprehensibility & C43 profitability & C44 reliability \\
\hline C41 interpretability & 1 & $1 / 3$ & $1 / 2$ & $1 / 5$ \\
\hline C42 comprehensibility & 3 & 1 & 2 & $1 / 2$ \\
\hline C43 profitability & 2 & $1 / 2$ & 1 & $1 / 3$ \\
\hline C44 reliability & 5 & 5 & 2 & 1 \\
\hline
\end{tabular}

Annotation: $\mathrm{CR}=0.0054$.

2) Determine the unweighted hypermatrix: Each column in the hypermatrix is a sort vector based on an element.

3) Determine the weight of each element in the hypermatrix, that is, normalize each column in the matrix.

4) Computation of weighted hypermatrix: SD software uses eigenvector method to obtain normalized eigenvectors and fill in hypermatrix column vectors according to two or two judgment matrices.

5) Calculate the limit hypermatrix: Use the power method to find the n-th power of the hypermatrix until the column vectors of the matrix remain unchanged. The final weights of the indicators are listed in Table IV.

TABLE IV. WEIGHT OF INFORMATION QUALITY INDEX IN SUPPLY CHAIN

\begin{tabular}{|c|c|c|c|c|c|}
\hline $\begin{array}{c}\text { First level } \\
\text { index }\end{array}$ & $\begin{array}{l}\text { Local } \\
\text { weight }\end{array}$ & $\begin{array}{l}\text { Global } \\
\text { weight }\end{array}$ & Two level index & $\begin{array}{l}\text { Local } \\
\text { weight }\end{array}$ & $\begin{array}{l}\text { Global } \\
\text { weight }\end{array}$ \\
\hline \multirow{4}{*}{$\begin{array}{l}\text { B1 sound } \\
\text { information }\end{array}$} & \multirow{4}{*}{0.15042} & \multirow{4}{*}{0.058759} & C11 consistency & 0.02239 & 0.013646 \\
\hline & & & C12 accuracy & 0.07585 & 0.04622 \\
\hline & & & C13 redundancy & 0.0144 & 0.008774 \\
\hline & & & C14 integrated & 0.01227 & 0.007479 \\
\hline \multirow{3}{*}{$\begin{array}{l}\text { B2 useful } \\
\text { information }\end{array}$} & \multirow{3}{*}{0.19997} & \multirow{3}{*}{0.078114} & C21 adequacy & 0.02849 & 0.017361 \\
\hline & & & C22 completeness & 0.06917 & 0.042152 \\
\hline & & & C23 simplicity & 0.05615 & 0.034216 \\
\hline \multirow{5}{*}{$\begin{array}{l}\text { B3 reliable } \\
\text { information }\end{array}$} & \multirow{5}{*}{0.28188} & \multirow{5}{*}{0.11011} & C31 accessibility & 0.08433 & 0.051388 \\
\hline & & & C32 maintainability & 0.01008 & 0.006141 \\
\hline & & & C33 reusability & 0.01842 & 0.011222 \\
\hline & & & C34 security & 0.01969 & 0.011996 \\
\hline & & & C35 timeliness & 0.06046 & 0.036842 \\
\hline \multirow{4}{*}{$\begin{array}{l}\text { B4 available } \\
\text { information }\end{array}$} & \multirow{4}{*}{0.36773} & \multirow{4}{*}{0.143646} & C41 interpretability & 0.06288 & 0.038315 \\
\hline & & & C42 comprehensibility & 0.17942 & 0.109333 \\
\hline & & & C43 profitability & 0.11283 & 0.068756 \\
\hline & & & C44 reliability & 0.17318 & 0.105531 \\
\hline
\end{tabular}

\section{Result analysis}

As can be seen from Table IV, among the four criteria, availability information accounts for the largest weight (36.8\%), followed by reliable information (28.2\%), accounting for the least proportion of robust information $(15.0 \%)$. It can be inferred that users have higher expectations of service information quality than product information quality in the supply chain. In the secondary index, the weight of comprehensibility, reliability, profitability, accessibility and accuracy ranked the top five, while the weight of redundancy, integration and maintainability ranked the bottom. It can also be seen from these indicators that the index weight proportion related to profitability is relatively high, which directly reflects that as an enterprise aggregate, the supply chain is still the highest criterion for profit.

\section{CONCLUSION}

At this point, the information quality index system in the supply chain has been constructed, and the selection and weight of the indicators in the system reflect the difference of information users' requirements on information quality. The index system can be used as a framework to evaluate supply chain information quality. However, to further obtain the final information quality level of an enterprise in a supply chain, it is necessary to obtain the specific score of the enterprise under the index, and the sum of the product of the score of each index and the weight of the corresponding index (i.e., the weighted average result) is the final information quality level of the enterprise. In the field of information theory research, more and more scholars have conducted researches on quantitative evaluation methods of data quality aiming at the specific scoring methods of information quality under different indicators. For example, Han Jingyu ${ }^{[8]}$, et al. proposed a data quality quantification method in the context range to achieve automatic data quality assessment. Starting from the essential attributes of information, these studies provide the mathematical model of the quality of quantitative research data itself, which enhances the accuracy of information quality evaluation.

The data collection stage of the above index weight measurement method is still dominated by qualitative analysis (quantitative analysis is adopted in the data analysis stage), relying on expert knowledge and experience. In addition, because the survey has not been carried out in a large range of regions, the obtained score is not universal and representative of the industry considering the differences in the requirements of different information quality indexes among supply chains of different industries. However, the research process and evaluation system construction method presented in this paper are still of high applicability.

\section{ACKNOWLEDGMENT}

This work was supported by National Natural Science Foundation of China (Grant No.71671089, 71171110).

\section{REFERENCES}

[1] Mo Zu-ying.Review of information quality research at home and abroad [J]. Intelligence work, 2015,(02).

[2] Richard Y W. A Product Perspective on Total Data Quality Management [J].Communications of the ACM, 1998,41(02): 58-65.

[3] Krol BG,et al. Digital Soi1 Mapping with Limited Data[C]. International Institute for Geo-InformationScience and Earth Observation (ITC), Postbus6, .7500AA, Enschede, the Netherlands, 2008. 
[4] Mouzhi Ge, Helfert, Markus. Impact of Information Quality on Supply Chain Decisions.Journal of Computer Information Systems [J].Summer, 2013, 53(04):59-67.

[5] Li C, Zhou H, Zhou X. Data Quality Assessment in Hydrological Information Systems [J]. Journal of Hydroinformatics, 2015, 17(04):640-661.

[6] Beverly K K, Diane M S. Information Quality Benchmarks: Product and Service Performance [J].Communications of the ACM, 2002(04):
184-192.

[7] Yu Shun-kun,Zhou Li-sha,Li Chen. Application research of anp-fuzzy method in power enterprise performance evaluation [J].Chinese Management Science, 2013(01).

[8] Han Jiong-yu,Song Ai-bo,Dong Yi-sheng.Data quality dimension quantization method[J].Computer Engineering and Application, 2008(36). 